\title{
EPAA reinforces action on dissemination
}

\author{
2009 EPAA Annual Conference
}

Workshop on Dissemination

The European Partnership for Alternative Approaches to Animal Testing (EPAA) focussed on Dissemination of $3 R$ s information in its Conference on $6^{\text {th }}$ November 2009. Besides some important recommendations for improving dissemination, the Conference demonstrated that, as EPAA moves into its fifth year, it has reached a new level of maturity. Not only has it advanced the knowledge and use of alternative methods, but it has stepped up to a new degree of impact and reputation.

European Commission Vice-President Günter Verheugen commented on the EPAA's evolution in his address to the conference. But above all, it is the decision to extend the activities of EPAA beyond its initial five years that shows that everyone involved with it now recognises the EPAA's value and potential.

The partnership has proven its value as an inclusive platform for dialogue and scientific collaboration and for tackling areas not taken up by other programmes or bodies, said Odile de Silva, the industry co-chair. Commission DG Enterprise and Industry Director Georgette Lalis expressed "definite interest" in continued cooperation. Industry participants further confirmed that, despite the current economic pressures, industry's commitment to the $3 \mathrm{Rs}$ and EPAA remains intact beyond the initial phase of five years.

The conference reviewed the EPAA's achievements in developing and transferring technologies that have the potential to lead to large reductions in the use of animals in research, and in improvements in communication with regulators and actions related to validation of alternative methods.

\section{For an increased efficiency}

To increase its efficiency and coordination, EPAA has reorganised its initial five working groups into three platforms: Science, Regulation and Dissemination.

The platform on Science will identify priorities for future research and spot the gaps and opportunities to improve animal welfare, including transferring opportunities across sectors. "We need sound science in order to base any new development in the 3Rs," said Odile de Silva.

But since science must be taken up to regulatory levels, and not just in Europe, the new platform on Regulation will con- tinue the EPAA focus on overcoming barriers to regulatory acceptance, facilitating implementation and monitoring legislative developments.

The creation of a platform on Dissemination and communication is the logical response to bridging the current gap between knowledge and practice. There is at present no systematic process to ensure widespread uptake once a new method is accepted.

It is no longer sufficient, EPAA feels, to rely on ad hoc solutions and the dedication of individuals. The work of the taskforce on dissemination is being taken forward now by the new Dissemination platform.

\section{Spreading knowledge}

The Conference devoted most attention to a theme that has acquired increasing importance over the past four years: the need to spread knowledge about 3Rs advances among researchers, validators, regulators and test users - in a word, dissemination. The Conference therefore examined work carried out on dissemination and in particular the results of a workshop on this topic that was held on $5^{\text {th }}$ November 2009 (see below).

Günter Verheugen himself made the point in his opening address: "It is essential that the potential of $3 \mathrm{Rs}$ and progress in the development of alternative approaches is brought to the attention of regulators and that those who work on the promotion of the 3Rs are aware of regulators' needs and requirements".

EPAA has always identified dissemination as a key issue. "It is in the background of all our activities and workshops," said Magda Chlebus from the European Federation of Pharmaceutical Industry Associations. Now dissemination is firmly embedded as a key stream of activity.

\section{EPAA's 2009 Poster award highlighted dissemination}

To reinforce the focus on dissemination of information on 3Rs, a thematic poster exhibition and competition was held as part of the EPAA 2009 Annual Conference.

EPAA invited companies, academia, research institutes and other organisations to provide posters describing, in lay lan- 
guage, initiatives related to the dissemination of 3Rs information and expected 3Rs impact (enhancing 3Rs development, uptake and regulatory acceptance).

The aim of the poster session was to gather and highlight initiatives at national or international level, indicating synergies and complementarity between different approaches. In total, 13 posters were presented.

The 2009 award, a prize of $€ 1,500$ to be used for 3Rs-related activities, was granted to M. Vivier and V. Rogiers of ecopa (the European Consensus Platform for Alternatives) for their poster: "ecopa, partner in dissemination of results in different EU projects".

- The winning poster can be viewed on the EPAA website at: http://ec.europa.eu/enterprise/epaa/4_events/ann_conf_2009/ posters_13_v_rogiers.pdf

- The 2009 progress report is available on the EPAA website at: http://ec.europa.eu/enterprise/epaa/4_events/ann_conf_2009/ annual_report_2009.pdf

- The full report of the conference is available at:

http://ec.europa.eu/enterprise/epaa/4_2_conf_2009.htm

\section{EPAA's Workshop on Dissemination of 3Rs information}

(Brussels, $5^{\text {th }}$ November 2009)

One of the key challenges in promoting the $3 \mathrm{Rs}$ is making sure that the available information gets out to those who can make use of it. That means the regulatory bodies, those in industry who are using animals in tests, but also the scientists who are actual or potential test developers. This was the challenge taken up by the EPAA workshop on Dissemination of 3Rs Information to Enhance Research, Acceptance and Uptake of 3Rs in Brussels on $5^{\text {th }}$ November, which brought together industry, academia, regulators and organisations promoting 3Rs methods, concluding various activities throughout 2009 as an input to the 2009 Conference.

\section{EPAA as a 3Rs market place for ideas}

"You cannot use what you don't know about," Joachim Kreysa of the European Commission's Joint Research Centre told the workshop. The statement is simple, yet it encapsulates one of the key challenges in work on the $3 \mathrm{Rs}$ - making sure that the information that is available gets out to those who can use it. That means first and foremost the regulatory bodies, but not only them: it must also reach those in industry who are performing animal tests.

At the end of the workshop, the stakeholders present - from industry, regulators, users and bodies promoting 3Rs methods - were in broad agreement about what they need to know, how they need to know it, and how to encourage a greater flow of knowledge among and between them all.

The key concept that emerged was of a "3Rs marketplace" where the EPAA serves as what Phil Botham from Syngenta called an "honest broker service", bringing together research- ers with ideas for possible new methods and industry and regulators looking for solutions.

The 3Rs marketplace is one of a raft of ideas that the workshop took forward to the EPAA conference the next day. These ideas were not suddenly invented by the workshop. They have been maturing over many months as part of a strategic examination by the EPAA of the issue of dissemination.

\section{Mind the gaps}

What information is missing? That was a question that the EPAA asked Jill Craig from The Centre to answer. Her findings, after a structured process whereby stakeholders were surveyed twice, the second time with the EPAA's assessment of their initial responses and proposals for progress, were clear.

First, the problem is with the quality rather than the quantity of information available. Here the crucial gaps are in knowing what regulators want, in access to full and accurate testing data, in information about validation status (and the process of validation), and in information on progress in the private sector on alternative methods.

Second, the information as it is currently available is poorly presented and organised. Stakeholders want to be able to access information on two levels: basic overviews in lay terms; and links and leads to more scientific and detailed information.

Third, Craig pinpointed a definite need for more emphasis on facilitating and organising dialogue. "There is too much emphasis on information and not enough on interpretation of that information." A major obstacle is that there are no mechanisms for feedback between regulators on the one hand and developers and users on the other. The result is mutual ignorance: the regulators complained that they don't know what is going on, said Craig, while the test developers say they are not told what information to provide.

Fourth, and perhaps surprisingly, Craig found no major differences of opinion between the stakeholder groups. Instead, she found different starting points: policymakers and regulators want more communication and exchange of information; educators, method developers, users - in short, scientists - are more interested in access to quality information, especially peer-reviewed information. Armed with these findings, the EPAA Dissemination Taskforce came up with three possible solutions:

- A proactive push mechanism to address the lack of access to quality information;

- EPAA-sponsored structured dialogue to address the problems of knowing what regulators want;

- EPAA awards to encourage new young scientists into the 3Rs area.

It was the first of these three ideas that attracted the most discussion, which eventually consolidated around the concept of the 3Rs marketplace. Could a body like the EPAA create a marketplace for ideas, so that people developing new approaches could go there and meet like-minded people? Since 
the EPAA sits between industry and the public, and is linked with industry and the regulators, it should be an ideal body to act as an "honest broker".

For the coming generation of scientists that link with the regulators could be crucial. Nynke Kramer from the Institute for Risk Assessment Sciences, the Netherlands, spoke up for that generation: "As young scientists we don't really know what regulators want. We know what we can do, but it would be really nice if the EPAA comes in as a broker - but it must be a proactive broker," she said.

If the conference had a leitmotif - apart from dissemination - it would be the well-known question of relations with regulators: what do they want, how can others talk to them, how can they be convinced to take up new ideas? How weak can a dataset be before the regulatory authorities reject it?

However, it's not all one-sided. Craig's surveys for the EPAA by The Centre looked at a mix of regulators. The story they told was that they go looking for the information - in journals, for example - but that in general "only industry" ever sends information in to them.

Engagement with regulators will be achieved by "an intricate learning" process, said Simon Webb from Procter \& Gamble. It is all the more necessary, he thought, since regulators are always going to want freedom to consider things on a case- by-case basis. Uncertainty about what regulators want is "not a dissemination problem, but a relationship one", he said.

\section{Conclusions of the workshop}

The first conclusion to be distilled from the discussion is that the workshop agreed, in Botham's words, "that it is worth trying to excite the EPAA and others in the idea of the EPAA providing an honest broker service, which we would call a marketplace."

The second conclusion is that progress will only come by doing something concrete, even if small. Botham called for "smallscale experiments, a few things next year", where the EPAA can test the water and see how well the experiments have gone.

Thirdly, dialogue with regulators must continue, in various forms. "We should ask them not just what information they want pushed to them, but also ask, in confidence, what they see as their information gaps."

The full report of the workshop is available on the EPAA website (www.epaa.eu.com).

\section{Correspondence to}

Cornelis Brekelmans

Adviser

European Commission

Directorate General for Enterprise and Industry

e-mail: entr-epaa@ec.europa.eu

\title{
Animal suffering and distress - what are the limits of ethical defensibility?
}

\author{
Bad Boll, Germany, $5^{\text {th }}-7^{\text {th }}$ March 2010
}

The introductory lecture at the Protestant Academy Bad Boll by Peter Kunzmann, professor of ethics in Jena, dealt with the difference between our treatment of animals held as pets or for experimental purposes, e.g. rabbits. The fact that this ambivalence is gaining recognition and has elicited protest is the consequence of an improvement in ethical valued put on animals by society. Associated contradictions may be found both in the Austrian and German Animal Protection Laws. In the lecturer's opinion, this ambivalence follows from different types of animal-human relationships and may differ between cultures. Kunzmann criticised the categorisation of animals into higher and lower orders and the related special status of primates. He suggested that animal protection should be approached from the animal's perspective and that the problem lies less in unfair but rather in inadequate treatment, e.g. the instrumentalisation of animals.

The Swiss jurist Gieri Bolliger from the Stiftung für das Tier im Recht showed, using dehorning of cattle as an exam- ple, how ethical defensibility must be determined according to $\S 1$ of the German Animal Protection Law. The procedure must be justified and commensurability must be demonstrated. The Law requires in some but not all areas that expected benefits must outweigh distress caused. Commensurability requires that the procedure must be adequate and necessary to reach the legitimate purpose. In the example, although dehorning is adequate to reduce the risk of injury for animal and handler, this goal may also be reached by changing the stable design. This result argues against dehorning on ethical grounds although it is still commonly practiced.

Thomas Richter, ethologist at Nürtingen-Geislingen University, discussed whether animal welfare can be evaluated using animal welfare indices. In his opinion, animal welfare depends on a positive mental state of the animal. Neither animal welfare indices referring to the animal's housing, nor the relationship between the handler and the animal or physiological parameters, such as heart rate and stereotypy, are suitable 